Verheul, W., Finset, A., Holt, E., Lauritzen Stensrud, T., Bensing, J.M. Is pain patients' psychophysiological arousal while watching their videotaped medical interview similar to their arousal during participation inthis medical interview? International Journal of Psychophysiology: 2011, 79(2), 305-310

\begin{tabular}{|l|l|}
\hline Postprint Version & 1.0 \\
\hline Journal website & $\underline{\text { http://dx.doi.org/10.1016/j.ijpsycho.2010.11.007 }}$ \\
\hline Pubmed link & $\underline{\text { http://www.ncbi.nlm.nih.gov/pubmed/21112356 }}$ \\
\hline DOI & $10.1016 /$ j.ijpsycho.2010.11.007 \\
\hline
\end{tabular}

This is a NIVEL certified Post Print, more info at http://www.nivel.eu

\title{
Is pain patients' psychophysiological arousal while watching their videotaped medical interview similar to their arousal during participation in this medical interview?
}

\author{
WILLIAM VERHEUL ${ }^{\mathrm{A}}$, ARNSTEIN FINSET ${ }^{\mathrm{B}}$, ERIK HOLT $^{\mathrm{B}}$, TONJE LAURITZEN STENSRUD ${ }^{\mathrm{B}}$ AND JOZIEN M. \\ BENSING $^{\mathrm{A}, \mathrm{C}}$ \\ ${ }^{a}$ NIVEL (Netherlands Institute for Health Services Research), Utrecht, The Netherlands \\ ${ }^{\mathrm{b}}$ Department of behavioural science, Institute of Basic Medical Sciences, Faculty of Medicine, University of \\ Oslo, Oslo, Norway \\ ${ }^{c}$ Faculty of Social and Behavioural Science, Utrecht University, Utrecht, The Netherlands
}

\begin{abstract}
Showing videos of medical consultation as a proxy for participation is being increasingly applied in research in order to let patients (re-)experience social interaction in medical settings. If subjects do indeed experience the interaction process when watching this on video, then they should show similar patterns in physiological arousal as when actually participating. We assessed whether watching one's own interaction in a medical setting on video lead to the same skin conductance activity (SC) as when participating in that interaction. Fifteen women with fibromyalgia participated in a medical interview and, after a break, watched the video of this interview. Skin conductance activity was measured throughout the medical interview and, again, while the participants watched their own video. Coherence in SC between these two conditions was assessed. In eleven subjects $(73 \%)$ a significant positive coherence between the two measurements was found, indicating that watching your own videotaped consultations evokes comparable psychophysiological arousal in most but not all participants. This physiological coherence might be an indication that people are capable of re-experiencing their interaction process by watching replays of these situations, although further research is needed. The positive coherence also supports skin conductance as a reliable moment-to-moment measure for physiological arousal throughout the doctor-patient interaction process. The next step should be linking the changes in physiological arousal to what exactly is happening at that moment in the interaction between doctor and patient. This could provide support for the validity of experimental designs in which standardized videotaped medical visits are shown to patients. More research is needed on predictors of (non-)coherence in certain subjects.
\end{abstract}

\section{INTRODUCTION}

Interactions between patients and their healthcare providers are important interpersonal events with a potential impact on a person's well being and health (de Haes and Bensing, 2009). Several systematic 
reviews have summarized research documenting how patient-healthcare provider interaction may influence patients' health and health-related outcomes ([Di Blasi et al., 2001], [Griffin et al., 2004], [Ong et al., 1982] and [Stewart, 1995]). As such, there is an interest to how subjects respond to specific communicative behaviours. In those kind of studies, the method of showing videos of medical consultation as a proxy for participation is being increasingly applied in order to let patients re-experience their consultation ([Arborelius and Timpka, 1991], [Eide et al., in press] and [Verheul et al., 2010]) or to expose a group of subjects to the same consultation ([Ellington et al., 2008], [Fogarty et al., 1999] and [Schmid Mast et al., 2005]).

The validity of using videos as a proxy for actual social interaction is plausible because of insights from neuro-cognitive sciences: humans can infer the mental states, including emotions, by adopting the perspective of the person in action by matching or tracking their states with the 'resonance' of our own mental states. This is evidenced by research on mirror neurons, which play an important role in interpersonal perception, showing simultaneous patterns of activation in brain areas subserving perception of behaviour and areas responsible for the actual carrying out of that behaviour ([Gallese, 2007], [Gallese and Goldman, 1998], [Gallese et al., 2004], [Wicker et al., 2003] and [Singer et al., 2004]). Thus, if subjects do indeed experience the interaction process when watching this on video, then they should show similar patterns in physiological arousal as when actually participating. We expect that such a concordance will be most likely to be present, when subjects can re-experience their own interaction.

The use of skin conductance level measurement is attractive to assess that concordance, because it can be applied continuously so responses can be assessed on a moment-to-moment basis throughout the interaction. Also, skin conductance has already been used in the field of marital therapy and parent-child interaction to assess the concordance between actual interaction and "re-experiencing" the interaction by watching it on video. Levenson et al found a concordance in moment-to-moment skin conductance between subjects interacting with their partner and while watching the video of that interaction (Gottman and Levenson, 1985). In a study by Lorber (Lorber, 2007), mothers interacted with their children and then watched that interaction on video. The results show that mothers physiologically re-experienced their interactions at a global level, but the moment-to-moment time series analyses indicated that skin conductance showed significant concordance in only a minority part of the time series. As mentioned, in a medical context such validity studies are still lacking.

The main goal in this paper is to examine whether subjects' phsyiological arousal measured throughout an interview in a medical healthcare setting is similar to subjects' arousal when the actual interaction is replaced by re-experiencing through video. This goal was accomplished by investigating the coherence between patients' skin conductance during an interview and during viewing the video of that interview on a moment-to-moment basis. Our research question is: do patients in a clinical interview in a medical setting show similar skin conductance activity when viewing the video of the interview as when participating in this interview? We hypothesized that there would be a positive coherence between patients' arousal measured during the medical interview and during the viewing of the video.

\section{MATERIALS AND METHODS}

\subsection{Subjects}

For this study, 18 female fibromyalgia patients participating in a larger study on medical communication were included. Subjects were between 28 and 50 years old. All subjects were inpatients of the Jeløya Rehabilitation Center, Norway and took part in a four week rehabilitation programme. Inclusion criteria were a clinical diagnosis of fibromyalgia, being female and absence of other chronic pain complaints. Three patients had to be excluded because of equipment failure during the interview or video viewing procedure or being SC non-responders (no or hardly any change in skin conductance through entire experiment). Skin conductance data of 15 patients were analyzed.

\subsection{Procedures}

The study was approved by the Regional Ethics committee of Eastern Norway. Patients were invited to participate by the hospital staff. If they showed interest, they received written information and signed an informed consent form. The hospital staff ensured that subjects met the inclusion criteria. After giving their informed consent, an appointment for the experimental procedure was made. 
The experimental procedure took place in the clinic. Subjects were welcomed and introduced to the experiment by a research assistant. After filling in PANAS ([Staud et al., 2006] and [Watson et al., 1988]), see section on measurement below) patients were prepared for skin conductance measurement by attaching the electrodes while assuring that measurement was neither dangerous nor painful. Patient were told that they would have a consultation with a psychologist who would ask them questions about their illness.

Subjects were given about five minutes to get used to the measurement system and to relax, while listening to relaxing music, during the last two minutes of this period, baseline measures were taken. Then, an interviewer entered the room, introduced herself, and conducted a clinical interview about the patient's illness. The interview focused on the following topics:

- The patient's trajectory towards the diagnosis of fibromyalgia

- Her experiences with healthcare providers in dealing with her illness

- The influence of the illness on her daily life.

Because of the content of the interview, the setting within the hospital and the interviewer wearing a physician's coat, the interview closely matched a consultation with a healthcare provider. Subjects were told, as part of their informed consent, that they would have an interview about their illness for research purposes. Skin conductance (SC) measurements were recorded throughout the interview. Subsequently, PANAS was re-administered.

After 20 min (in which subjects took part in another interview which was part of the larger encompassing research project), subjects were instructed to attempt to re-experience the interview while watching the video of the interview. Subjects then watched their video which was projected on a screen (life-sized), while, again, SC was continuously recorded. Afterwards patients completed PANAS again. Patients were then debriefed.

\subsection{Measurement}

Skin conductance activity was measured using the Biopac MP150 system which was connected to a Windows XP operated laptop running Acknowledge 3.8 (Biopac) data acquisition program. The Biopac GSR 100C transducer module was used for exciting a $0.5 \mathrm{~V}$ constant current and 200 samples per second were recorded. Disposable gel finger electrodes (type: $\mathrm{Ag}-\mathrm{AgCl}$, contact area: $1 \mathrm{~cm}$ diameter) were placed on the second and third finger of the subject's non-dominant hand. The interview was recorded using a digital video camera connected to a second windows XP operated notebook computer and the video signal was directly fed into the Observer XT 7 program (Noldus). Both computers where connected and Acknowledge and Observer synchronized the video signal with the physiological data. The video viewing procedure was also filmed and this video was used to synchronize the physiological data of the participation and the review procedure.

A low pass filter was used to eliminate any high frequency noise components of the skin conductance signal (cut off frequency $1 \mathrm{~Hz}$, number of coefficients: 800). SC data per second was exported to Stata 11. The first $30 \mathrm{~s}$ and the last $30 \mathrm{~s}$ were removed as participants were moving in the beginning and end of the interview. Other very obvious movement artefacts (identification by video-observation) were removed. Following, $5 \mathrm{~s}$ intervals of the interview or interview viewing were defined. Data was detrended to a stationary time series by regression of $\mathrm{SC}$ on the time-variable and exponentiated products of the time variable. The SC data was then normalized and plotted trough time per patient.

Self-reported emotional state was measured by the Positive Affect Negative Affect Schedule (PANAS), an often used and well-validated measure of positive and negative affect ([Staud et al., 2006] and [Watson et al., 1988]).

\subsection{Analyses}

We used Stata 10 for analyses. We calculated mean skin conductance level (SCL) values and their sd for baseline, interview, and video watching phase and determined the increase in SCL compared to the baseline. The partial correlation coefficient between mean SCL during interview and SCL during video watching controlling for baseline was calculated.

Time series (ARMA) models were then fitted then to assess the significance of the relationship. We controlled for autocorrelation (SCL values being predicted by previous SCL values) by including up to second order autoregressive predictors, depending on partial autocorrelation function plot. Single side Ztests were used to calculate $p$-values as we only tested if a positive relation was present. Standardized $b$ (beta) values, standard errors and $\mathrm{p}$ values are reported. 
We then explored possible predictors of concordance by assessing the correlation between concordance beta values and, respectively change in positive and negative affect, mean SCL change during video procedure minus baseline and the time-series beta-values and the variance in SCL values.

To check the construct validity of this coherence, we also analyzed if self-reported emotional state after the interview and after video viewing (after controlling for baseline emotional state) shows coherence in the same direction as SCL.

\section{RESULTS}

We collected $16108(2 \times 8054 \mathrm{~s})$ of SC data points corresponding to a mean duration of $8.95 \mathrm{~min}$ per interview. The mean SCL was $2.53 \mu \mathrm{S}(\mathrm{sd}=0.34)$ during the interview and $3.58 \mu \mathrm{S}(\mathrm{sd}=0.58)$ during the video procedure.

In Table 1, mean SCL values for baseline, interview phase and video watching phase are listed. In all but one subjects, there was a mean increase in mean SCL compared to baseline measurement for both the interview phase and the video phase. One subject showed a only limited increase in mean SCL in the interview phase and no increase in the video watching phase. No subject showed a decrease in means SCL compared to baseline. Paired t-tests showed that both the interview procedure and the video procedure lead to significantly higher mean SCL compared to baseline $(\mathrm{p}<0.001)$. Overall there is a high 'test-retest reliability' between the interview and the video watching phase: their partial correlation coefficient controlling for baseline SCL is $0.87(\mathrm{p}<0.001)$.

\section{[TABLE 1. ]}

The time series regression models yielded significant beta-values in 11 out of the 15 plots $(73.3 \%$ ) (see Table 2). One plot (patient 6) showed a partial correlation which was very close to reaching statistical significance $(\mathrm{p}=0.06)$. In two other plots, coherence was visually discerned at most of the series, but with one or two large disturbances. One patient (nr 15) showed no coherence according to both visual inspection and the time series regression model (Table 1). To check if positive and significant beta-values were not due to inherent features of the SC series within individuals, thus producing spurious results, we performed time series models of interview SCL with their time-inverted SC video viewing series (i.e. where the last SCL value was taken as first value, the one but last as the second, etc.) of five randomly chosen subjects. We found that they all showed either no significant coherence or a significant negative coherence (because data were detrended to a stationary time series, this absence of a positive coherence cannot be because of the gradual decrease in SCL during each session: without detrending, the time-inverted series would tip around its middle point, automatically leading to a negative correlation). Concordance beta-values were not significantly related to changes in PANAS affect scores or mean change in SCL during the video procedure. Variance of SCL during the video watching procedure was also not significant, but showed a trend $(\mathrm{r}=0.42, \mathrm{p}=0.06)$.

\section{[TABLE 2.]}

The partial correlation coefficient between self-reported negative emotional state after the interview and after watching the video was $0.73(\mathrm{p}=0.001)$ while controlling for emotional state at baseline. The partial correlation coefficient between self-reported positive emotional state after the interview and after video watching was $0.40(p=0.08)$ while controlling for emotional state at baseline.

Fig. 1 illustrates a series in which we discerned a high coherence (patient 1 , time series $\beta=0.36$ ). Fig. 2 exemplifies a series in which a series with reasonably high coherence (patient 5 , time series $\beta=0.28$ ) can be found (very good after $3 \mathrm{~min}$ ), but with large disturbances between the 2 nd and 3rd minute. In Fig. 3, a series is shown in which we could not discern coherence (patients 15 , time series $\beta=0.06$ ). The continuous lines in the figures depict SC-values during the interview and the dashed lines depict SC-values during watching the video. 


\section{[FIGURE 1, FIGURE 2 AND FIGURE 3]}

\section{DISCUSSION}

This study assessed the coherence in skin conductance activity in fibromyalgia patients while they were participating in a clinical interview in a medical setting and while they were watching the same interview on video immediately afterwards. Mean SCL during participation and video watching showed a significant and high positive correlation while controlling for baseline values. Time series models showed positive coherence in skin conductance level on a moment-to-moment basis during the two procedures in 11 out of 15 subjects. Self reported negative emotional state measured after the interview and video viewing procedure showed also positive coherence. These findings suggest that re-viewing one's own interaction can re-evoke the same pattern in physiological arousal as measured with skin conductance. Since the rises and drops in SCL occurred on the same moments in (watching) the interview, it is likely that these changes in SCL occurred because of what was happening in the interview. It is not plausible that this coherence is caused by individual variability, as evidenced by the lack of positive coherence between SCL during the interview and the time-inverted (thus a-synchronous) SCL series during watching the interview.

Although this study does not validate the use of videotaped conversations as a method for re-experiencing an interaction process, this study does make it plausible that watching one's own interaction on video can evoke the same physiological arousal. This finding is in line with the idea that video-viewing procedures can serve as a methodology to simulate social interaction in a medical context, at least when it concerns skin conductance as an outcome.

The experience of viewing the interaction is of course different from the experience of the original interview for several reasons, such as the social difference of directly interacting with a person or not (e.g. having the memory of being in the situation versus experiencing it for the first time). If we can change the social situation, the medium of the message, the memory load, the task demands, and the knowledge versus unexpectedness of the next question, and none of these affects SCL (as would be shown by lower concordance), then SCL is either immune to these changes, or the imagining of the re-experiencing is more powerful in determining SCL than all of the other factors that differ in the two measurement periods. This is particularly relevant for studies in which patients judged or rated the interaction in their medical consultation while watching the video, such as the study by Arborelius and Timpka (1991) where patients and physicians (on different occasions) commented on their recorded consultations regarding the method and the kind of information received and the study by Eide et al. (in press) where patients pointed out the moments when they felt concern or worry during a medical interview using a video-watching procedure. The results of our study indicate that the same moments in the medical interview aroused them during participation as while re-experiencing the consultation by watching the video. Although physiological measures were not applied in these two cited studies, it seems likely that moments deemed important to patients were also physiologically arousing: physiological arousal does not always mimic subjective arousal, but they often do correspond to a certain extent ([Levenson and Gottman, 1983] and [Levenson and Gottman, 1985]). Our study thus makes it more plausible that moments indicated as important or arousing by patients in a video procedure do indeed reflect what they felt during the actual consultation.

In order to provide a stricter experimental control to the study of correlates of communicative behaviour, studies increasingly assess effects of specific communication elements by exposing subjects to videos of patient-healthcare provider communication ([Ellington et al., 2008], [Fogarty et al., 1999] and [Schmid Mast et al., 2005]). This offers the possibility to expose a subject multiple times to the same communication or multiple subjects to the same communication.

Our results correspond to Gottman and Levenson's results (1985) who also found that moment-to-moment skin concordance during interaction and video re-experiencing are concordant. Our results are partly compatible with Lorber (2007), who found a relation between mean SCL during interaction and video reexperiencing Albeit not the goal of this study, its results can be also interpreted as support for SCL as a process measure of the level of general arousal during the medical interview. The coherence of SCL patterns during the repeated exposure to same communication sequence supports that SCL has adequate test-retest reliability: the communication elements within the total interaction process consistently evoke similar changes in SCL on a moment-to-moment basis. This opens up the possibility to relate specific communication elements within an ongoing medical interaction to physiological arousal assessed by SCL. 
It should then be taken into account that skin conductance is a very general measure of autonomic activity and will represent a subjects' emotional activation, but also more general arousal related to the physical and social context, such as loudness of voice, speech onset and gaze of mothers-child interaction, but relatively little concordance on a moment-to-moment basis. This can be due to the context of the experiment. Gottman and Levenson (1985) proposed that a quite strong emotional response may be necessary for physiological reliving to occur. It might be that this was the case for our interviews with fibromyalgia patients in which concordance occurred. However, there was no relation between changes in patient's subjective affect and the concordance in skin conductance. The trend we found for the relation between variance of SCL responses during the video procedure and concordance, might indicate that there are individual differences in the extent to which subjects can (or choose to) re-experience the interview during the video procedure (Rottenberg et al., 2007). It is for instance known that subjects respond differently to video when they adopt a first person perspective, compared to when they watch as an 3rd person observer (Ruby and Decety, 2004). As such, patients' empathic ability might influence their capability to feel present in patient-provider interaction as shown on video ([Lamm et al., 2007] and [Moriguchi et al., 2007]). From research on virtual reality, it is known that this sense of presence is positively influenced by the amount of emotion that is evoked (Riva et al., 2007). Therefore it seems important to check for the sense of presence as well of the motivation of participants in studies using video to simulate patient-provider interaction.

In interpreting the beta values of the time series models, one should take into account that there are factors that cause artifacts and by that disrupt the coherence. During visual inspection of the videos, we could identify sighing, laughing and certain movements as sources of disturbances in the coherence. We noticed that most small movements did not interfere with measurement, but movement of the fingers to which the electrodes were connected did. This study lacks control for breathing, although deep sighing (which will make SCL suddenly increase and decrease) could be identified in some videos of the medical interview. It would have been better to control for effects of breathing on SCL by means of a respiratory belt (Dawson et al., 2007), although this might have been too invasive for our sample. It is encouraging that measurement of skin conductance did not seem to interfere with the communication in the interview: use of psychophysiological measures for assessing patient-healthcare provider is still relatively rare ([Ellington et al., 2008] and [Finset et al., 2006]), but as known from other fields, it can be a valuable addition in outcome measures (Cacioppo et al., 2007).

\subsection{Limitations of the study}

A limitation of this study is its small sample of patients. But although our sample was small, we were able to show statistically significant coherences. Because SCL could be measured continuously during the procedures, a representation of patients' arousal throughout the interview and video-viewing consisting of many data points could be gathered, rather than having only before and after measurement.

The increase in mean SCL compared to baseline might possibly be caused by increased absorption of electrode cream into the skin, increasing conduction. Alternatively, one might expect a decrease in SCL because of habituation, since exposure to the interaction is repeated.

It should also be noted that our sample exists only of women with fibromyalgia. It is possible that other groups would respond with different patterns of electrodermal activity when exposed to the video of medical communication, although we do not have hypotheses why this would be the case.

Another limitation could be that the medical communication used in this study consisted of an interview in which no diagnosis or other new medical information was given by the interviewer. Results could be different for more invasive sequences of medical communication. However, we suggest that since such information will often evoke stronger emotions and thus evoke a stronger sense of presence, the coherence in arousal between participant and viewer could be increased (Riva et al., 2007).

It might be more difficult for patients to attain a sense of presence when watching a videotaped medical visit of other patients, for instance if they differ from the original participants in preferences for communication or demographical characteristics. We cannot tell from this study. The next step is thus to establish whether new observers show that same response at the same moments in medical consultations.

\section{CONCLUSIONS}

Patients can show more or less the same level of physiological arousal at the same moments in time when they watch their clinical interview in a medical interaction on video compared to when they were taking 
part in that interview. This study can be seen as a step in the validation of studies using subjects who reexperience communication sequences on video ([Ellington et al., 2008], [Fogarty et al., 1999] and [Schmid Mast et al., 2005]), although future research should point out whether cognitive and emotional effects when watching communication on video are comparable with participation in that interaction process. By applying a strictly controlled, experimental design, this type of video studies could provide a more precise insight in the impact of certain communication behaviours on patients' physiological arousal, which has added value above the behavioural and self report measures that are currently applied in most research on doctor-patient communication.

Furthermore, it is important to do more research into examples of non-coherence, as this might be caused by procedural or technical faults as well as by specified subject characteristics for instance a lack of empathic capabilities (Jabbi et al., 2007). Nevertheless, we think that we have embarked on a promising research avenue, which could have a profound influence on the methodology of doctor-patient communication research.

We planned this study because we think video viewing of patient health provider communication might be a viable approach to achieve simulation of communication processes for research purposes. Video viewing by is already extensively used, but the validation of the approach is somewhat left behind. Our study makes it plausible that during the video viewing procedure, patients' psychophysiological arousal can act as a proxy for the arousal during the medical interview.

\section{ACKNOWLEDGEMENTS}

We would like to acknowledge and thank the patients of Jeløya Rehabilitation Clinic for their participation, Jeløya Clinic staff, in particular Dr. Sigrid Hørven Wigers for their help with organizing this study, Dr. Ellen Hamaker en Peter Spreeuwenberg for their statistical advice and Dr. Sandra van Dulmen, Liesbeth van Vliet and the anonymous reviewers for their comments on earlier versions of this paper. We are grateful to the Norwegian Research Council for awarding the first author with a scholarship to visit Oslo University and take part in this research project.

\section{REFERENCES}

Arborelius and Timpka, $1991 \mathrm{E}$. Arborelius and T. Timpka, Comparison of patients' and doctors' comments on video-recorded consultations, Scandinavian Journal of Primary Health Care 9 (2) (1991), pp. 71-77.

Cacioppo et al., 2007 J.T. Cacioppo, L.G. Tassinary and G.G. Berntson, Handbook of Psychophysiology, Cambridge University Press (2007).

Dawson et al., 2007 M.E. Dawson, A.M. Schell and D.L. Filion, The Electrodermal System. In: J.T.

Cacioppo, L.G. Tassinary and G.G. Berntson, Editors, Handbook of Psychophysiology (3rd ed.),

Cambridge University Press, Cambridge/New York (2007), pp. 159-180.

de Haes and Bensing, $2009 \mathrm{H}$. de Haes and J. Bensing, Endpoints in medical communication research, proposing a framework of functions and outcomes, Patient Education and Counseling 74 (3) (2009), pp. 287-294.

Di Blasi et al., 2001 Z. Di Blasi, E. Harkness, E. Ernst, A. Georgiou and J. Kleijnen, Influence of context effects on health outcomes: a systematic review, Lancet 357 (9258) (2001), pp. 757-762.

Eide et al., in press Eide, H., Eide, T., Rustøen, T., and Finset, A., (in press). Patient validation of cues and concerns identified according to Verona coding definitions of emotional sequences (VR-CoDES): A videoand interview-based approach. Patient Education and Counseling, Corrected Proof. doi:10.1016/j.pec.2010.04.036.

Ellington et al., 2008 L. Ellington, S. Matwin, B.N. Uchino, S. Jasti, D. Roter and W.N. Dudley, The body's response to health care provider communication: the impact of dominant versus facilitative styles, Journal of Applied Biobehavioral Research 13 (2) (2008), pp. 67-85.

Finset et al., 2006 A. Finset, P.K. Graugaard and K. Holgersen, Salivary cortisol response after a medical interview: the impact of physician communication behaviour, depressed affect and alexithymia, Patient Education and Counseling 60 (2) (2006), pp. 115-124.

Fogarty et al., 1999 L.A. Fogarty, B.A. Curbow, J.R. Wingard, K. McDonnell and M.R. Somerfield, Can 40 seconds of compassion reduce patient anxiety?, Journal of Clinical Oncology 17 (1) (1999), p. 371. 
Verheul, W., Finset, A., Holt, E., Lauritzen Stensrud, T., Bensing, J.M. Is pain patients' psychophysiological arousal while watching their videotaped medical interview similar to their arousal during participation inthis medical interview? International Journal of Psychophysiology: 2011, 79(2), 305-310

Gallese, 2007 V. Gallese, Before and below 'theory of mind': embodied simulation and the neural correlates of social cognition, Philosophical Transactions of the Royal Society of London. Series B, Biological Sciences 362 (1480) (2007), pp. 659-669. )

Gallese et al., 2004 V. Gallese, C. Keysers and G. Rizzolatti, A unifying view of the basis of social cognition, Trends in Cognitive Sciences 8 (9) (2004), pp. 396-403.

Gallese and Goldman, 1998 V. Gallese and A. Goldman, Mirror neurons and the simulation theory of mindreading, Trends in Cognitive Sciences 2 (12) (1998), pp. 493-501.

Gottman and Levenson, 1985 J.M. Gottman and R.W. Levenson, A valid procedure for obtaining self-report of affect in marital interaction, Journal of Consulting and Clinical Psychology 53 (2) (1985), pp. 151-160.

Griffin et al., 2004 S.J. Griffin, A.L. Kinmonth, M.W.M. Veltmn, S. Gillard, J. Grant and M. Steward, Effect on health-related outcomes of interventions to alter the interaction between patients and practitioners: $a$ systematic review of trials, Annals of Family Medicine 2 (6) (2004), pp. 595-608.

Jabbi et al., 2007 M. Jabbi, M. Swart and C. Keysers, Empathy for positive and negative emotions in the gustatory cortex, Neurolmage 34 (4) (2007), pp. 1744-1753.

Lamm et al., 2007 C. Lamm, C.D. Batson and J. Decety, The neural substrate of human empathy: effects of perspective-taking and cognitive appraisal, Journal of Cognitive Neuroscience 19 (1) (2007), pp. 42-58.

Levenson and Gottman, 1983 R.W. Levenson and J.M. Gottman, Marital interaction: physiological linkage and affective exchange, Journal of Personality and Social Psychology 45 (3) (1983), pp. 587-597.

Levenson and Gottman, 1985 R.W. Levenson and J.M. Gottman, Physiological and affective predictors of change in relationship satisfaction, Journal of Personality and Social Psychology 49 (1) (1985), pp. 85-94.

Lorber, 2007 M.F. Lorber, Validity of video-mediated recall procedures for mothers' emotion and child ratings, Journal of Family Psychology 21 (3) (2007), pp. 520-528.

Moriguchi et al., 2007 Y. Moriguchi, J. Decety, T. Ohnishi, M. Maeda, T. Mori and K. Nemoto et al., Empathy and judging other's pain: an fMRI study of alexithymia, Cerebral Cortex (New York, N.Y.: 1991) 17 (9) (2007), pp. 2223-2234.

Ong et al., 1982 L.M. Ong, J.C. de Haes, A.M. Hoos and F.B. Lammes, Doctor-patient communication: a review of the literature, Social Science \& Medicine 40 (7) (1982), pp. 903-918.

Riva et al., 2007 G. Riva, F. Mantovani, C.S. Capideville, A. Preziosa, F. Morganti and D. Villani et al., Affective interactions using virtual reality: the link between presence and emotions cyberpsychology and behavior : the impact of the Internet, Multimedia and Virtual Reality on Behavior and Society 10 (1) (2007), pp. 45-56.

Rottenberg et al., 2007 J. Rottenberg, R.D. Ray and J.J. Gross, Emotion Elicitation Using Films. In: J.S. Coan and J.L. Allen, Editors, Handbook of Emotion Elicitation and Assessment, Oxford University Press, Oxford (2007), pp. 9-28.

Ruby and Decety, 2004 P. Ruby and J. Decety, How would you feel versus how do you think she would feel? A neuroimaging study of perspective-taking with social emotions, Journal of Cognitive Neuroscience 16 (6) (2004), pp. 988-999.

Schmid Mast et al., 2005 M. Schmid Mast, A. Kindlimann and W. Langewitz, Recipients' perspective on breaking bad news: how you put it really makes a difference, Patient Education and Counseling 58 (3) (2005), pp. 244-251.

Singer et al., 2004 T. Singer, B. Seymour, J. O'Doherty, H. Kaube, R.J. Dolan and C.D. Frith, Empathy for pain involves the affective but not sensory components of pain, Science (New York, N.Y.) 303 (5661) (2004), pp. 1157-1162.

Staud et al., 2006 R. Staud, C.J. Vierck, M.E. Robinson and D.D. Price, Overall fibromyalgia pain is predicted by ratings of local pain and pain-related negative affect - possible role of peripheral tissues, Rheumatology (Oxford, England) 45 (11) (2006), pp. 1409-1415. )

Stewart, 1995 M.A. Stewart, Effective physician-patient communication and health outcomes: a review, Canadian Medical Association Journal 152 (9) (1995), pp. 1423-1433.

Verheul et al., 2010 W. Verheul, A. Sanders and J. Bensing, The effects of physicians' affect-oriented communication style and raising expectations on analogue patients' anxiety, affect and expectancies, Patient Education and Counseling 80 (3) (2010), pp. 300-306.

Watson et al., 1988 D. Watson, L.A. Clark and A. Tellegen, Development and validation of brief measures of positive and negative affect: the PANAS scales, Journal of Personality and Social Psychology 54 (6) (1988), pp. 1063-1070.

Wicker et al., 2003 B. Wicker, C. Keysers, J. Plailly, J.P. Royet, V. Gallese and G. Rizzolatti, Both of us disgusted in my insula: the common neural basis of seeing and feeling disgust, Neuron 40 (3) (2003), pp. 655-664. 
Verheul, W., Finset, A., Holt, E., Lauritzen Stensrud, T., Bensing, J.M. Is pain patients' psychophysiological arousal while watching their videotaped medical interview similar to their arousal during participation inthis medical interview? International Journal of Psychophysiology: 2011, 79(2), 305-310

\section{TABLES AND FIGURES}

\section{Table 1}

SCL means per patient for baseline, interview and video watching phase.

\begin{tabular}{|c|c|c|c|c|c|c|c|c|}
\hline \multirow[t]{2}{*}{ Subject } & \multicolumn{2}{|c|}{ Baseline } & \multicolumn{3}{|c|}{ Interview } & \multicolumn{3}{|c|}{ Review } \\
\hline & $\begin{array}{l}\text { Mean } \\
\text { SCL } \\
(\mu S)\end{array}$ & $s d$ & $\begin{array}{l}\text { Mean } \\
\text { SCL } \\
(\mu S)\end{array}$ & $s d$ & $\begin{array}{l}\Delta \text { ( } \mu S \text {, comp. } \\
\text { to baseline) }\end{array}$ & $\begin{array}{l}\text { Mean } \\
\text { SCL } \\
(\mu S)\end{array}$ & $s d$ & $\begin{array}{l}\Delta \text { ( } \mu S \text {, comp. } \\
\text { to baseline })\end{array}$ \\
\hline 1 & 1.57 & 0.36 & 2.33 & 0.13 & 0.76 & 3.73 & 0.18 & 2.16 \\
\hline 2 & 2.02 & 0.19 & 3.56 & 0.16 & 1.54 & 3.9 & 0.18 & 1.88 \\
\hline 3 & 0.59 & 0.06 & 0.98 & 0.08 & 0.39 & 2.07 & 0.2 & 1.48 \\
\hline 4 & 1.66 & 3.47 & 4.33 & 0.76 & 2.67 & 8.69 & 0.53 & 7.03 \\
\hline 5 & 1.21 & 0.07 & 1.45 & 0.18 & 0.24 & 1.55 & 0.22 & 0.34 \\
\hline 6 & 0.56 & 0.11 & 1.22 & 0.24 & 0.66 & 2.26 & 0.23 & 1.70 \\
\hline 7 & 1.96 & 0.08 & 3.59 & 0.12 & 1.63 & 4.69 & 0.14 & 2.73 \\
\hline 8 & 1.96 & 0.14 & 2.35 & 0.12 & 0.39 & 3.29 & 0.19 & 1.33 \\
\hline 9 & 4.37 & 0.59 & 5.48 & 0.97 & 1.11 & 7.95 & 0.8 & 3.58 \\
\hline 10 & 0.49 & 0.09 & 1.1 & 0.19 & 0.61 & 1.72 & 0.15 & 1.23 \\
\hline 11 & 0.51 & 0.03 & 0.83 & 0.03 & 0.32 & 0.93 & 0.15 & 0.42 \\
\hline 12 & 2.06 & 0.08 & 2.95 & 0.29 & 0.89 & 4.23 & 0.41 & 2.17 \\
\hline 13 & 1.11 & 0.15 & 2.1 & 0.13 & 0.99 & 1.73 & 0.38 & 0.62 \\
\hline 14 & 1.81 & 0.14 & 3.3 & 0.41 & 1.49 & 4.46 & 0.41 & 2.65 \\
\hline 15 & 2.9 & 0.15 & 3.05 & 0.28 & 0.15 & 2.9 & 0.14 & 0.00 \\
\hline
\end{tabular}


Verheul, W., Finset, A., Holt, E., Lauritzen Stensrud, T., Bensing, J.M. Is pain patients' psychophysiological arousal while watching their videotaped medical interview similar to their arousal during participation inthis medical interview? International Journal of Psychophysiology: 2011, 79(2), 305-310

Table 2

Coherence between SC during the medical interview and while watching the video.

\begin{tabular}{|c|c|c|c|}
\hline Patient & $\beta$ & S.E. & $\mathrm{p}$ \\
\hline 1 & 0.36 & 0.11 & $\leq \underline{0.001}$ \\
\hline 2 & 0.19 & 0.11 & $\overline{0.04}$ \\
\hline 3 & 0.24 & 0.10 & $\overline{0.01}$ \\
\hline 4 & 0.19 & 0.09 & $\overline{0.01}$ \\
\hline 5 & 0.28 & 0.10 & $\leq \overline{0.01}$ \\
\hline 6 & 0.18 & 0.12 & $\overline{0.06}$ \\
\hline 7 & -0.01 & 0.09 & 0.46 \\
\hline 8 & 0.23 & 0.13 & 0.04 \\
\hline 9 & 0.41 & 0.11 & $\leq \overline{0.001}$ \\
\hline 10 & 0.15 & 0.04 & $\leq \underline{0.001}$ \\
\hline 11 & 0.36 & 0.18 & 0.03 \\
\hline 12 & 0.15 & 0.13 & $\overline{0.13}$ \\
\hline 13 & 0.40 & 0.09 & $\leq \underline{0.001}$ \\
\hline 14 & 0.27 & 0.08 & $\leq \overline{0.001}$ \\
\hline 15 & 0.06 & 0.11 & $\overline{0.28}$ \\
\hline
\end{tabular}

$\mathrm{p}$ values considered significant when $\mathrm{p}<0.05$.

Fig. 1. EXAMPLE OF HIGH COHERENCE IN SC (PATIENT 1).

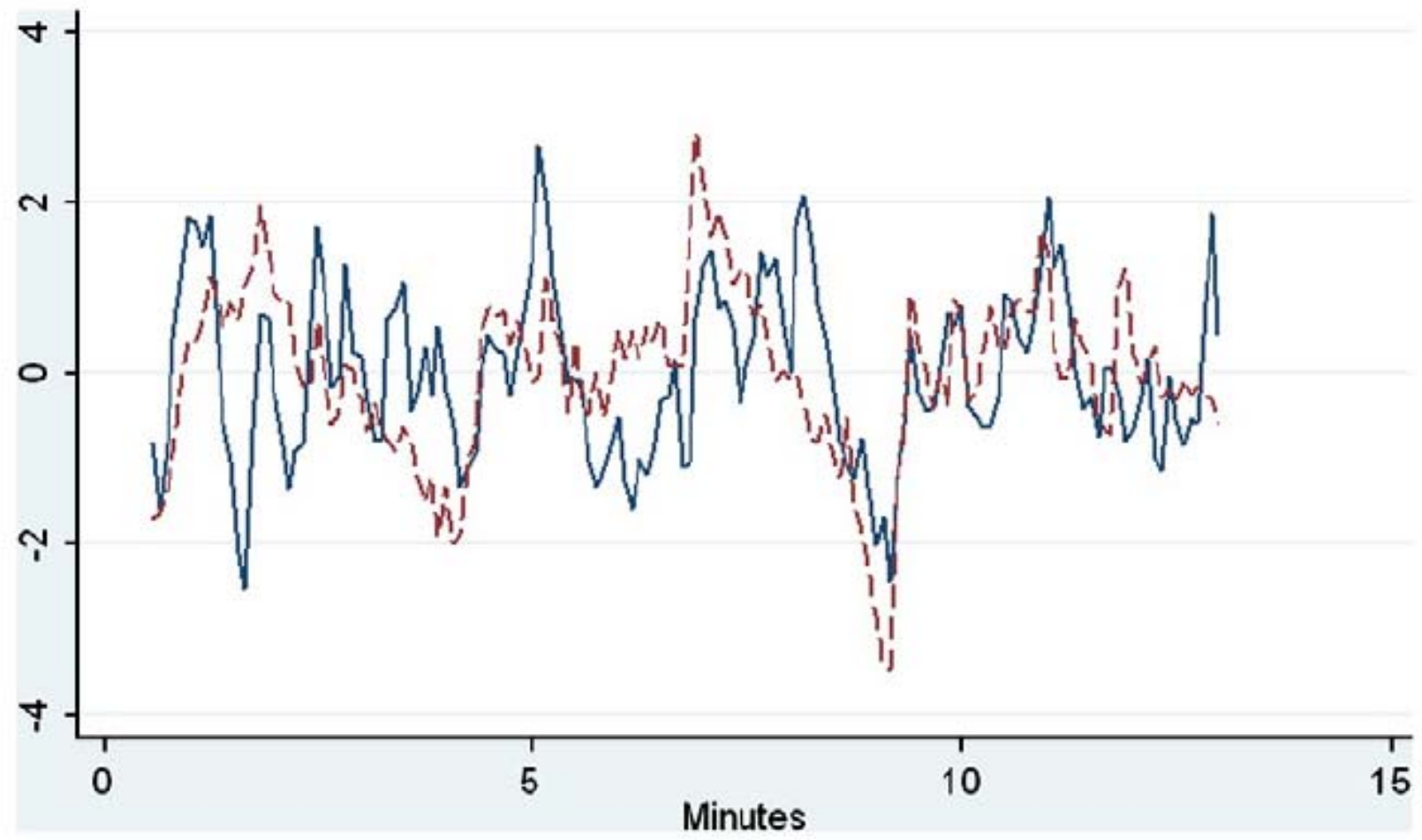


Verheul, W., Finset, A., Holt, E., Lauritzen Stensrud, T., Bensing, J.M. Is pain patients' psychophysiological arousal while watching their videotaped medical interview similar to their arousal during participation in this medical interview? International Journal of Psychophysiology: 2011, 79(2), 305-310

FIG. 2. EXAMPLE OF POSITIVE COHERENCE IN SC WITH SOME DISTURBANCES (PATIENT 5).

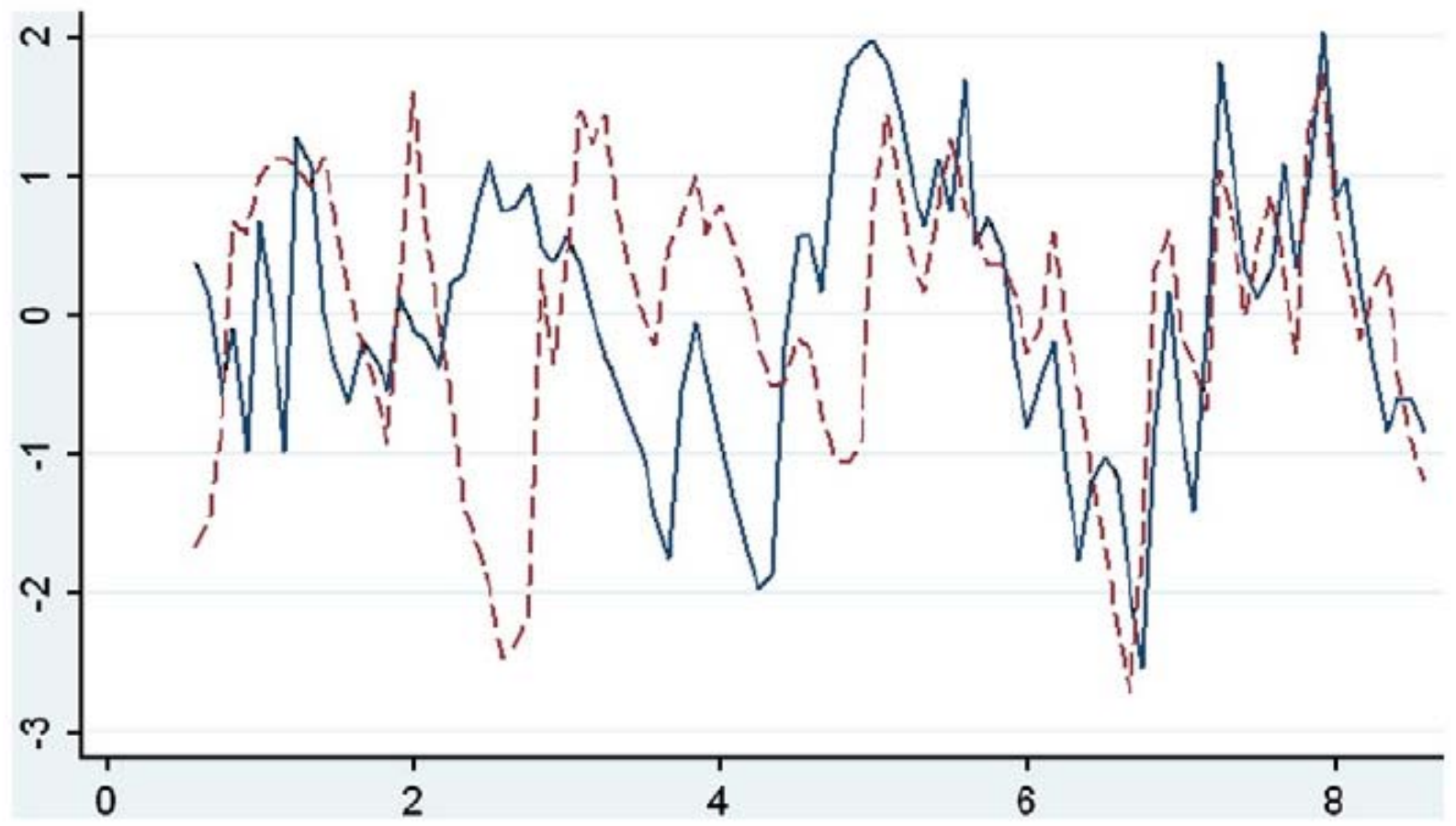

FIG. 3. EXAMPLE OF NO POSITIVE COHERENCE IN SC (PATIENT 15).

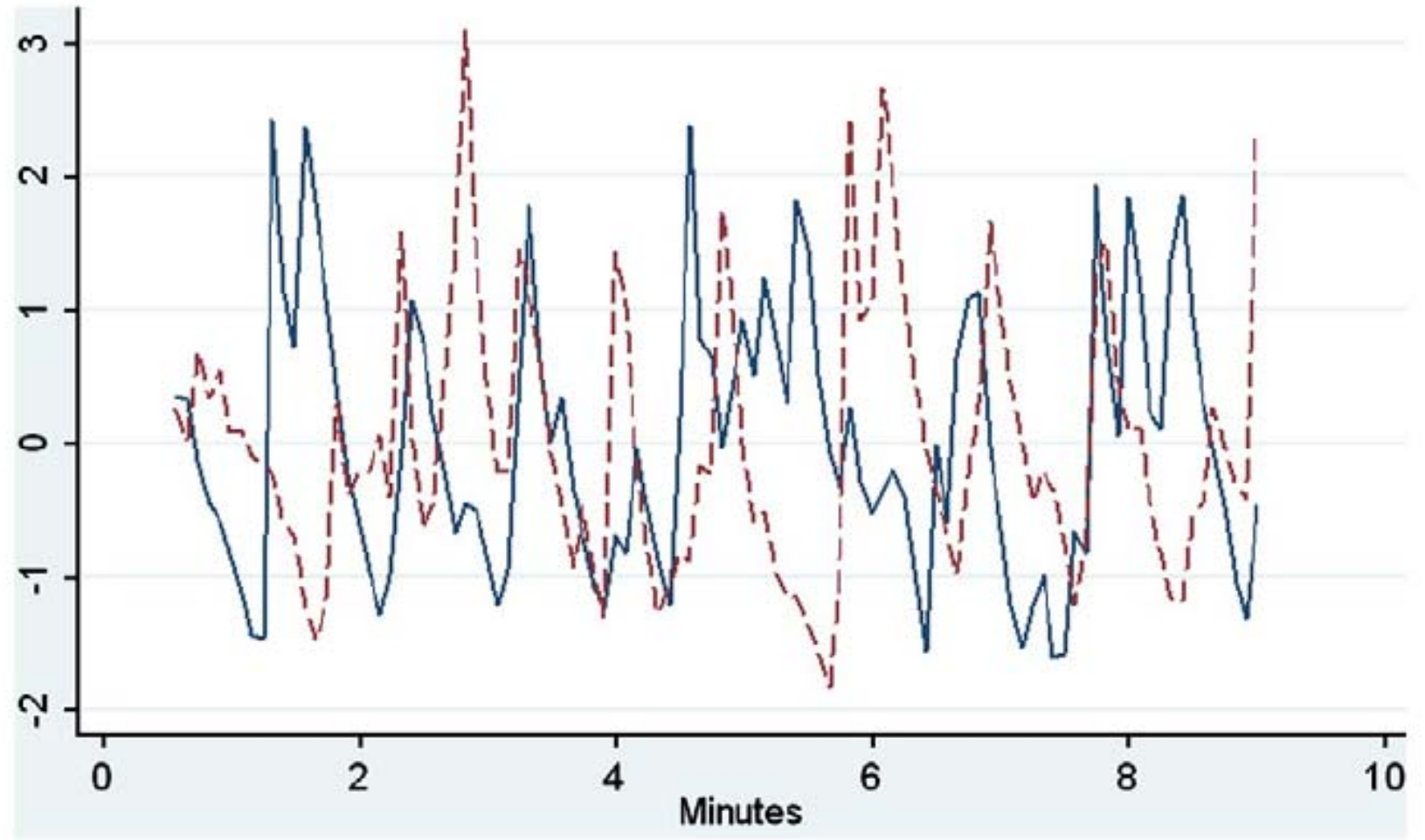

